\title{
A INFLUÊNCIA DE BAUDELAIRE NA POESIA DE EDUARDO GUIMARAENS
}

Lívia Petry Jahn ${ }^{1}$

RESUMO: Baudelaire foi o precursor do modernismo e de toda uma visão diferenciada sobre poesia, a partir de seu livro As Flores do Mal. Influenciou sobremaneira a poesia feita na França e no Brasil, especialmente a poesia de Eduardo Guimaraens que guarda referências explícitas à obra poética de Baudelaire. Em seu livro, A Divina Quimera, Eduardo Guimaraens retoma imagens, temas e motivos da poesia de Baudelaire, bem como trabalha as questões de sonoridade e sinestesia tão caras ao poeta francês. Com poesias escritas na língua francesa, o poeta brasileiro busca unir os motivos do simbolismo à busca por musicalidade tão característica deste movimento estético. E aliado a isso escreve em português poesias que dialogam com Baudelaire explicitamente como no caso da poesia "De profundis clamavi" e "Alma das Coisas", ambas inspiradas em poesias do bardo francês. Sendo assim, Baudelaire não só influenciou a poesia moderna como também seus precursores, no caso, os simbolistas. É através de sua influência na poesia brasileira e sul-riograndense que surgiu uma nova forma estética e poética que permanece influenciando a escrita até nossos dias.

PALAVRAS-CHAVE: Simbolismo Francês, Baudelaire, poesia, teoria das correspondências, Eduardo Guimaraens, As Flores do Mal.

\begin{abstract}
Baudelaire was the forerunner of Modernism and of a whole differentiated view on poetry, from the publication of his book The Flowers of Evil on. He greatly influenced poetry written in France and Brazil, especially the poetry of Eduardo Guimaraens, which resembles the poetry of Baudelaire in an explicit way. In his book The Divine Chimera, Eduardo Guimaraens reinstates images, themes and motifs of Baudelaire's poetry, in addition to working on poetic aspects such as sonority and synesthesia, which are so dear to the French poet. With poems written in French, the Brazilian poet seeks to unite the motifs of symbolism to the search of musicality, which is so characteristic of this aesthetic movement. Besides, he writes poems in Portuguese that dialogue with Baudelaire explicitly, as in the case of the poem "De profundis clamavi" and "Soul of Things", both inspired by poems of the French bard. Thus, we may conclude that Baudelaire has not only influenced modern poetry, but its precursors as well, in this case, the Symbolists. And through his influence on Brazilian and southern Brazilian poetry, a new aesthetic and poetic form has arisen, which has been influencing our writing until today.
\end{abstract}

KEYWORDS: French Symbolism, Baudelaire, poetry, theory of correspondences, Eduardo Guimaraens, The Flowers of Evil.

\footnotetext{
${ }^{1}$ JAHN, Lívia Petry. Doutoranda em Literatura Portuguesa e Luso-Africanas da Universidade Federal do Rio Grande do Sul. E-mail: liviapetry@terra.com.br;liviajahn@gmail.com
} 


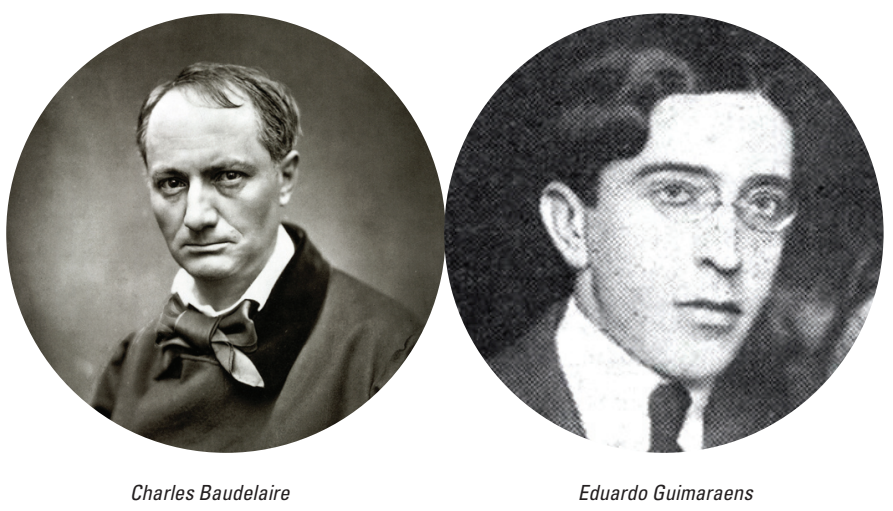

\section{O Simbolismo no Brasil}

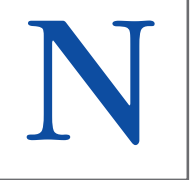

o Brasil, o Simbolismo surgiu em 1893 com a publicação de "Broquéis" e "Missal", de Cruz e Souza e expandiu-se pelo país atingindo poetas de relevância, entre eles, Alphonsus de Guimaraens, Emiliano Perneta e Eduardo Guimaraens. Assim como em Paris, surgem no Brasil grupos simbolistas formados em torno de jornais e revistas, a exemplo da Folha Popular (Rio de Janeiro, 1891), da Padaria Espiritual (Fortaleza, 1892), da Rosa-Cruz (1901) e da Fon-Fon (Rio de Janeiro, 1908).

Entretanto, a estética simbolista no país acabou misturando-se ao parnasianismo no apego às formas métricas e no cultivo do soneto. Porém, o simbolismo rompeu alguns parâmetros, mostrou-se mais audacioso no interior dos versos através do deslocamento da cesura e até da ausência dela, da divisão do alexandrino segundo medida ternária e finalmente na inovação do verso livre. Além disso, os simbolistas inspirados em temas medievais ressuscitaram a vilanela, o rondó, o rondel, a balada. A Idade Média também surgiu na temática abordada especialmente em Eduardo Guimaraens, onde se fazem presentes o amor cortês e o ideário cristão. No entanto, outros poetas simbolistas também fizeram uso do mesmo tipo de misticismo e trouxeram para o país uma poesia plena de traços transcendentais como, por exemplo, Alphonsus de Guimaraens e Cruz e Souza.

Num corte eclético os simbolistas brasileiros também abordaram temas diversos como o cotidiano burguês e simplista de Mário Pederneiras, o helenismo e o paganismo de Emiliano Perneta, o hermetismo de Êrnani Rosas e, por fim, o evolucionismo e o panteísmo de Augusto dos Anjos.

No Rio Grande do Sul houve todo um ajuste do simbolismo europeu à cor local expressa nas poesias de Felipe D’Oliveira, Alceu Wamosy, Álvaro Moreyra, José Picorelli, Mansueto Bernardi e Eduardo Guimaraens. Dentre estes poetas, Eduardo Guimaraens foi aquele que mais seguiu de perto a poesia feita na França, tendo seus poemas traços e temas influenciados por Baudelaire, Verlaine, Mallarmé e Samain. Diferentemente de seus conterrâneos, sua poesia também sofreu influência da lírica italiana, especialmente de Dante e D’Annunzio. Assim, Eduardo Guimaraens não 
só inovou em termos formais, métricos, temáticos, mas também recuperou toda uma tradição poética advinda dos trovadores provençais da Idade Média e que serviu de base para a grande poesia europeia feita depois dela como é o caso de Dante.

Em seu diálogo com a tradição, Eduardo Guimaraens manteve-se sempre atento. Prova disso é o próprio título que deu ao seu livro publicado em 1916: A Divina Quimera, numa alusão à Divina Comédia. Porém, como bem nota Mansueto Bernardi, A Divina Quimera aproxima-se mais de Vita Nuova, ao desenvolver a temática do amor. Como se fosse uma sinfonia à bem-amada, este livro é dividido em Prelúdio, composto de três partes, e Sonata Sentimental, dividida em duas partes. Basicamente tratando do amor, estes poemas são atravessados por uma atmosfera de sonho e melancolia na qual o eu-lírico se vê preso, feito estivesse vivendo um exílio. Ele canta a dor do amante que só tem de seu o próprio amor. Clama aos céus por um pouco de paz diante da dor e da eterna ânsia que sente. Canta o ardor febril de Dante por Beatriz numa analogia à sua própria situação e divisa as raias da morte como a única possibilidade de encontro quando o amor cessa de existir.

Além desta obra, Eduardo Guimaraens teve editados em 1944, após sua morte, mais cinco livros que seu amigo Mansueto Bernardi juntou à Divina Quimera. São eles: Poemas à Bem-Amada, La Gerbe Sans Fleurs, Cantos da Terra Natal, Estancias de um Peregrino, Rimas do Reino dos Céus. Eduardo Guimaraens também teve publicados em 2002, sob o título de Dispersos uma série de poemas inéditos que foram organizados pela prof ${ }^{a}$ Maria Luíza Berwanger da Silva (UFRGS). Assim, este ensaio valeu-se de ambas as obras para traçar um panorama de sua poesia não só sob o ponto de vista das influências estéticas, mas principalmente no que toca à esfera metafísica que permeia seus poemas.

\section{A presença do Simbolismo francês e suas implicações metafísicas na obra de} Eduardo Guimaraens

Eduardo Guimaraens trouxe à palavra o feitiço que seus colegas franceses tanto argumentaram e sobre o qual escreveram: o dom de evocar, de sugerir estados de alma. A evocação, palavra transformada em código entre o humano e o divino.

E se a palavra é um meio de invocação, de feitiço, de profecia, será através da magia das palavras que ele irá expressar esta outra realidade do mundo: a realidade metafísica, eterna, que se expande através da consciência do homem perante a finitude, o tempo, a morte, o amor, o livrearbítrio.

Além disso, como bom simbolista, Eduardo Guimaraens inscreve em suas imagens o tanto de sonho, devaneio, sugestão, musicalidade, vaguidade, alegoria, símbolo e mitos, transformando a realidade do poema e do eu-lírico em outra realidade, para além da significação unívoca das palavras, exprimindo os vários sentidos que estas comportam, "abrindo" o poema às interpretações do leitor. Trazendo para dentro de sua obra o símbolo como "chave última de todas as coisas, como realidade sensível da língua ou como signo de um mundo ideal que ele designa", como afirma Philippe Forest.

Assim, a poesia de Eduardo Guimaraens bem como a de Mallarmé, Baudelaire, Verlaine, Samain e outros, não mais se volta "à descrição precisa e rígida de uma realidade exterior ou in- 
terior, mas à invenção da língua mesma dentro do texto, através do mistério no qual se regozijam autor e leitor. Desta estética do mistério participam em maior ou menor grau, todas as obras do simbolismo: a de Mallarmé construída por inteiro em torno de um vazio que a densidade do poema busca exprimir, a de Verlaine que também joga deliberadamente com o vago, a imprecisão, o deslocamento. Como escreveu Mallarmé, "é preciso haver sempre enigma em poesia". É este enigma que irá abrir as portas para uma outra dimensão da palavra poética. Afinal, a busca poética e estética do simbolismo resolve-se através do símbolo, neste movimento pelo qual "nossa realidade imediata se abre a uma dimensão mais alta e basicamente ideal na qual a palavra poética revela o sentido último do mundo".

Permitindo assim, uma plurissignificação da palavra, transformando-a em símbolo e, enquanto símbolo, buscando essa sublimação de percepções e de sensações, evocando um mundo ideal, sugerindo ao invés de apontar o objeto, sendo assim, a mais alta expressão da arte e a mais espiritualizada expressão do homem.

Para além do símbolo há também outro aspecto que influenciou sobremaneira a poesia de Eduardo Guimaraens e seus mestres: e aqui falamos da necessidade de musicalidade da palavra. Como disse Verlaine "de la musique avant toute chose".

$\mathrm{Na}$ busca pela força sugestiva, pelo poder evocador, a poesia simbolista irá encontrar na música o mistério da alma, a capacidade de elevar o espírito do homem, de provocar sensações, de fugir ao racional utilizando como artifício primeiro, o tempo, já que toda música é feita de pausas e compassos. A palavra musical será a procura mais árdua entre os simbolistas: a palavra pura, total, sonora. Ou seja, a palavra enquanto melodia, atingindo assim, os sentidos e o espírito do leitor. Desta forma, irá surgir uma musicalidade nova do verso, sendo cúmplice e acompanhando o símbolo, trazendo da música o élan e o segredo que a definem. Antes música, o poema fará emergir como que uma língua nova, a língua verdadeira da poesia. Não é à toa que Eduardo Guimaraens iniciará seu livro, A Divina Quimera, com um Prelúdio, e entre suas muitas poesias iremos encontrar Noturnos, Adágios, Cânticos, bem como poemas dedicados a Chopin e referências a Beethoven. Ainda assim, a musicalidade não estará presente só nos títulos e nas referências, mas no próprio encadeamento das poesias, em suas rimas, na escolha das palavras, na forma de construir os versos.

Temos, além disso, na poesia de Eduardo Guimaraens as sinestesias e as imagens através das quais o poeta cria a correspondência entre o mundo divino, o Ideal de Platão (o Bem, a Verdade, o Belo) e o mundo terreno, seja expressa através do amor divinizado, platônico, seja através da própria natureza, seja através do mito. Por isso, o discurso indireto de Eduardo Guimaraens caracteriza-se por uma profunda marca no compromisso simbolista ante a existência divina. Como escreve Anna Balakian, aqui "o mundo natural é ao mesmo tempo uma barreira e uma escala de símbolos do divino. Somente através do reconhecimento da dualidade entre nosso espírito e nossos sentidos pode o poeta aproximar-se da unidade final no futuro" (BALAKIAN, 1985, p. 35).

Sendo assim, "a multiplicidade de nossos sentidos deve ser vista apenas como uma indicação da sinestesia que poderá ocorrer no processo unificador da vida celestial" (BALAKIAN, 1985, p. 37).

É essa multiplicidade de sentidos que, Eduardo Guimaraens, através de sinestesias, musicalidade, simbolização, põe em seus poemas fazendo uma correspondência entre o mundo poético, 
o mundo natural e o mundo divino.

Há, além desta, outra preocupação do poeta: simbolizar os processos de passagem do tempo, unindo num mesmo poema, imagens que encerram o tempo linear e histórico da vida humana, o tempo cíclico da natureza $\mathrm{x}$ imagens que encerram o tempo eterno das divindades. A finitude, a ideia de morte física x morte espiritual, o amor como construção do divino em si e através do outro, a ideia de livre-arbítrio x destino, a síntese do humano através da busca pelo sagrado na mitologia e na poesia, fazem parte das imagens e ideias que Eduardo Guimaraens constrói em seus poemas.

A própria Divina Quimera numa alusão direta à Divina Comédia, divide-se também em círculos. O Céu, o Purgatório e o Inferno recheiam esta Quimera que, no entanto, eleva o amor do poeta desde o estado de melancolia e solidão, até o amor divino que tudo perpassa, tudo define. A própria imagem da amada transmuta-se em Anjo, Beata Beatriz, Madonna, atingindo o nível do divino, do Ideal, transformando os caminhos do desejo em sublimação do instinto e elevação espiritual. Outro ponto forte desta Quimera é a transformação de elementos da natureza em imagens da passagem do tempo, trazendo a ideia de finitude x eternidade. Outro aspecto ainda a ressaltar é a transformação da poesia em sonho, devaneio, onde o eu-lírico do poeta se entrega numa viagem interior, na busca do que está além da realidade, no mais intrínseco da alma. Como exemplo disso, temos o poema "Chanson Frêle" que lembra bastante a poesia de Mallarmé e sua "fleur absente de tous les bouquets", ou seja, o que existe é a essência da flor e não o objeto. Aqui neste caso, sua essência é feita de sonho:

\section{CHANSON FRÊLE}

Je rêve, crois-le bien, je rêve

Je rêve d'une douce fleur...

Je rêve d'une fleur de rêve!

D'une fleur dont l'âme s'élève

à toi toujours, ô ma Jolie,

à toi, comme une vieille odeur

d'amour et de mélancolie, comme le parfum de mon coeur, à toi toujours, ô ma Jolie!

Je t'offre cette rose fleur.

(Eduardo Guimaraens, D. Q., v. III, 1944, p. 252)

Aqui o poeta usa rimas internas e externas, aliterações, enjambement, anáforas (Je rêve) e uma chave-de-ouro que resume todo o poema. O poeta, através da musicalidade das palavras e da sinestesia, fala desta flor de sonho, com a qual sua alma se eleva a esta formosura suprema, a formosura da bem-amada. A sinestesia aparece também neste "velho odor de amor e melancolia", 
perfume de amor que o poeta oferece na estrofe final como uma rosa. A rosa mística do sonho, a rosa divina do amor.

Em "L'Embarquement pour Cythére", também podemos ver o uso da sinestesia no primeiro e segundo versos da primeira estrofe, onde "o céu se perfuma de flores" e "o ar é doce". Há rimas internas como o uso da palavra "Vous" e rimas externas e encadeadas em todo o poema. O verbo que finaliza a primeira estrofe dá à poesia este tom de chamamento, urgência, movimento, numa alusão ao tempo que já não pode ser preterido. Assim, a noite e a bruma soam como um alarme do poeta, feito quem prevê o inevitável, a passagem do tempo, a morte, o anoitecer do mundo, o fim do sentimento. Mas este não é um poema pessimista. Ao contrário, é um convite urgente à música, ao deleite, ao amor. Esta embarcação é uma metáfora que se esclarece no último verso: o barco é o coração do poeta. E neste coração soa a música de Verlaine, ouvimos de longe seus violões lânguidos na imagem das flautas e das guitarras que, sobre o barco, "enchem o ar de amor e canções bizarras".

$\mathrm{Na}$ terceira estrofe o eu-lírico se apresenta como o barqueiro, aquele que "rema com doçura”, e novamente faz o convite ao amor usando outra vez de verbos para impor o movimento e a urgência desta viagem interior rumo à alma, ao coração. Aqui novamente o poeta usa a sugestão, a música, a correspondência entre a palavra humana e o divino expressa no amor, no embarque da alma, na entrega do coração do poeta, no convite que o eu-lírico nos faz desde a primeira estrofe.

Pode-se notar, além disso, a utilização magistral deste símbolo, o barco, como travessia, transposição do estado interior para esta realidade que está além das palavras. O barco como símbolo da entrega do amor, da travessia para a vida. Há aqui um jogo com o mito de Caronte, também barqueiro, mas de outro rio. Enquanto Caronte atravessa as almas pelo rio Lete e as leva aos mundos inferiores, este outro barqueiro faz a travessia da alma para o amor, para a descoberta da plenitude, para o céu. Se o barco de Caronte simboliza a morte, o barco de Eduardo Guimaraens simboliza o coração, a vida:

\section{L'EMBARQUEMENT POUR CYTHÈRE}

Le ciel de fleurs se parfume

et l'air est doux.

Si vous vous attardez, la nuit viendra, la brume!

Embarquez-vous! Embarquez-vous!

Des flûtes et des guitares

sur le bateau

jouent des airs d'amour et des chansons bizarres.

L'amour est gai, le chant est beau!

Ne suis-je moi qui rame

avec douceur?

Venez! Embarquez-vous pour Cythère, mon âme!

Le bateau pour toi - c'est mon coeur. 
(Eduardo Guimaraens, D. Q., v. III, 1944, p. 252)

Neste poema podemos também divisar a influência das imagens míticas que o simbolismo recupera. Citera (Cythère) é a ilha mítica do "coração e das festas do amor" onde Vênus reina soberana. Este paraíso da mitologia será recuperado por poetas como Baudelaire (Viagem a Citera) e Verlaine (Citera). Eduardo Guimaraens recorre assim a um diálogo com ambos, Baudelaire e Verlaine, construindo uma poesia onde o amor triunfa e carrega consigo a alma através de imagens sugestivas e da música das palavras, dois aspectos que a poesia francesa do séc. XIX tanto privilegiou.

\section{A influência de Baudelaire na poesia de Eduardo Guimaraens}

Ideia recorrente na poesia de Eduardo Guimaraens, a transcendência e as correspondências também irão fazer parte do poema "Alma das Coisas". Aqui, usando o recurso do enjambement, rimas interpoladas e ricas, assonâncias, aliterações e verbos no presente do indicativo, o poeta traz para dentro dos versos um movimento contínuo e um tempo que atravessa a linearidade da existência definida em passado/ presente/ futuro para impor-se como eterno fazendo um jogo entre a finitude da vida humana x a eternidade da alma, de Deus. Neste jogo de reflexos, o poeta ressalta a importância desde a menor até a maior expressão da vida, culminando no ser humano e sua consciência. Consciência esta, que permite ao homem o re-conhecimento do infinito no finito, ou seja, do divino, como Eduardo Guimaraens expressa na sexta e sétima estrofes de seu poema. Onde ele fala "da paz destes rítmicos momentos" que trazem para nós a comunicação de algo maior, quando encontramos "transfundidos os sentidos e os pensamentos". Baudelaire costumava dizer que era através dos sentidos que o homem podia experienciar o sublime. Eduardo Guimaraens põe em seu poema quase a mesma ideia. Paradoxalmente, é na hora em que tudo parece adormecer que a consciência do poeta desperta: num despertar do olhar, dos sentidos perceptíveis, que podem "ver" o "quanto é vasta essa alma que em tudo canta":

\section{A ALMA DAS COISAS}

Nestes crepúsculos suaves,

à hora em que os mundos se iluminam, e quando as frontes se reclinam, tristes e graves,

para os abismos palpitantes

e cheios de ecos do passado, à luz do céu quase estrelado, sob os andantes

desta harmonia grandiosa, como não há de a criatura 
sentir a cósmica ternura

misteriosa

e fluida, com a qual se anima

tudo que existe, desde a aresta

da rocha ao monstro da floresta,

e que aproxima

da massa bruta o ser que pensa,

do infinito espaço o infinito

do humano espírito e do grito

da boca a imensa

paz destes rítmicos momentos, nos quais se mesclam, transfundidos

e a comunicar-se, os sentidos

e os pensamentos,

à hora em que a noite se levanta

e morre a tarde branda e calma, ao ver o quanto é vasta essa alma

que em tudo canta!...

(GUIMARAENS, D.Q., v. IV, 1944, p. 307)

Esta alma universal posta em versos por Eduardo Guimaraens será a expressão máxima da teoria de Emanuel Swedenborg, para quem "todas as coisas que existem na natureza, desde o que há de menor ao que há de maior são correspondências. A razão para que sejam correspondências reside no fato de que o mundo natural, com tudo o que contém, existe e subsiste graças ao mundo espiritual, e ambos os mundos graças à Divindade" (BALAKIAN, 1985, p. 40).

Esta teoria será também abordada no soneto "Correspondances", de Baudelaire. Em comum Baudelaire e Eduardo Guimaraens apresentarão a realidade não através das aparências, mas daquilo que se oculta atrás delas, sua essência. Como bem ressalta Álvaro Cardoso Gomes, "concebendo assim o mundo, o poeta descarta a ideia de que os objetos do real tenham sentido em si. Segundo Swedenborg estes não passam de símbolos do mundo espiritual, da Divindade. Cabe, portanto, ao homem, decifrá-los para conhecer o enigma do Universo" (GOMES, 1984, p. 39).

Assim, o poeta torna-se um vidente, um decifrador de símbolos, alguém capaz de enxergar a alma de tudo o que existe. Baudelaire e Eduardo Guimaraens se tornam próximos quando através de seus poemas descortinam o que está além da realidade objetiva e mostram o quanto as palavras de Swedenborg se aplicam a eles. Porém, se de um lado ambos falam a mesma linguagem, de outro Baudelaire se distancia na medida em que para ele as sinestesias dentro do poema não buscam um liame entre o céu e a terra, nem transportam o leitor a um estado divino, mas ao contrário, encontram conexões com as experiências sensoriais aqui na terra. Baudelaire vê a natureza como um "templo", uma "floresta de símbolos". Cabe ao homem decifrar esses símbolos que o "vêem, mas 
de olhos familiares". Para decifrar esses símbolos, o ser humano usa então os sentidos: a audição, o tato, o olfato, a visão, o paladar. Através deles, é que o homem se liga à unidade do universo. Essa unidade se exprime nos perfumes, nos sons, nas cores. Para apreendê-la é necessário ouvir o "doce som do oboé", ver "o verde das campinas", sentir "o perfume fresco como a carne das crianças". É através da expansão das sensações que o universo se expande e causa a nítida percepção de "embriaguez do ser e dos sentidos". Para Baudelaire o mundo da transcendência e da natureza, a essência do universo não é apreendida pela racionalidade, pelo pensamento, mas sim pela sensação, pelos sentidos. Esta será a diferença fundamental entre Baudelaire e Eduardo Guimaraens, para quem a transcendência se dá também através do pensamento. Assim, para o poeta brasileiro, "a harmonia grandiosa", "a cósmica ternura misteriosa" que "anima tudo o que existe" aproxima da "massa bruta, o ser que pensa". Desta maneira, a unidade do universo se manifesta quando na "paz destes rítmicos momentos, / nos quais se mesclam, transfundidos/ e a comunicar-se, os sentidos/ e os pensamentos". Ou seja, a racionalidade tem um papel fulcral na poesia de Eduardo Guimaraens e na sua busca por transcendência.

No entanto podemos ver em ambos os poetas a necessidade de suplantar as aparências para encontrar a verdade. Esta necessidade irá guiar Eduardo Guimaraens na criação de outro poema extremamente profundo também inspirado em Baudelaire. Porém, se ambos os poetas usam o mesmo título e as mesmas formas de construção do poema, suas obras irão diferir quanto à utilização das imagens. "De Profundis Clamavi" escrito em forma de soneto, irá apresentar rimas interpoladas e ricas, e todo um jogo de sonoridades feito principalmente de aliterações. No entanto, o clamor em versos de Baudelaire será um retrato do abismo ao qual sucumbe o eu-lírico: "horizonte de chumbo/ em que nadam na noite o terror e a blasfêmia". Este abismo vazio irá solidificar-se num "país mais nu do que a terra polar", num "sol gelado", numa noite que se compara àquela do "caos ancestral".

A dor máxima que atinge o sujeito lírico revela-se em sua própria tomada de consciência quando Baudelaire fala que o "mais vil animal no seu sono inconsciente", tem em sua suprema ignorância, um destino mais afortunado que o do eu-lírico. Já os versos de Eduardo Guimaraens tomarão emprestado o mesmo clamor profundo para falar do "eterno anseio", daquilo que faz de si a matéria para "toda a angústia humana e toda humana glória". Neste poema o amor se expressa num gemido exangue e melancólico, que em "vão interroga a sombra do infinito" para apenas "sorver, calado, a lágrima ilusória". Tudo é ilusão e mistério, a própria ânsia de amar é em si um enigma. Enigma que será a causa principal dos clamores do eu-lírico a Deus. Estes clamores também se originam "no profundo horror de esplêndida memória", na alma torturada e exangue que não encontra respostas para as principais questões da vida, e para a qual o amor não passa de uma triste ilusão. Assim, a figura de Deus aparece como a única possibilidade de resgate da paz perdida, de salvação, de bem-aventurança. Deus aparece aqui como o Ser onipotente e onipresente capaz de aplacar as angústias, as dores, as misérias. Só Ele pode levar o homem a encontrar a paz. Daí as interpelações que o poeta lhe faz: "Ouve, Deus de Sinai que tens o raio ao seio!/ Nós clamamos a ti pelos perdões supremos/ pela suprema paz ao nosso eterno anseio".

Utilizando-se de antíteses e anáforas, o poeta constrói elementos de tensão máxima em sua chave-de-ouro ao mesmo tempo em que faz da repetição uma nota de força maior. Assim, o 
eu-lírico faz uma interrogação que irá remeter-nos de volta ao início do poema. Ele pergunta qual a razão que leva o ser humano a viver em conflito consigo mesmo, torturado. Para isso usa de imagens bíblicas e remete o leitor ao "Éden em que sofremos", ao "Inferno em que gozamos". Não existe inferno ou paraíso, tudo se resume ao mesmo lugar quando a alma se vê angustiada, vazia, "conflituada". E se o horror, a dor, o sofrimento pertencem à esfera da alma, somente a essência suprema, o que chamamos Deus, pode aplacar tais estados de espírito. Somente Deus pode compreender a ânsia e a complexidade humanas e dar a elas uma forma de alento. Deus representará, portanto, o Ser que está acima das contingências, dos padecimentos. Ele é a própria essência da Eternidade e se traduz numa paz profunda, num perdão supremo, como o próprio poeta nos revela na terceira estrofe:

\section{DE PROFUNDIS CLAMAVI}

Deste profundo horror, de esplêndida memória, ouve, Senhor, o brado unânime e maldito que aos céus, vibrando, sobe! Ouve o sinistro grito que é toda a angústia humana e toda humana glória!

Ouve o que diz a boca exangue e merencória, de amor gemendo! E o lábio ardente do preceito que em vão interrogou a sombra do infinito! E que sorveu, calado, a lágrima ilusória!

Ouve, Deus de Sinai que tens o raio ao seio! Nós clamamos a ti pelos perdões supremos, pela suprema paz ao nosso eterno anseio!

E queremos saber por que nos torturamos!

E clamamos a ti do Éden em que sofremos!

E clamamos a ti do Inferno em que gozamos!

(GUIMARAENS, D.Q, 1944, p. 155).

Divisamos desta forma, as várias instâncias em que a figura de Deus aparece representada na poesia de Eduardo Guimaraens, seja como a "alma que em tudo canta", "o infinito espaço", seja como "Deus de Sinai", seja na figura da bem-amada que não é feita de "humana essência", mas vem das "cousas místicas do espaço", seja através da Eternidade simbolizada na morte, seja através da força que rege o destino dos mitos.

Podemos inferir, desta maneira, as diferenças entre a visão mística de Baudelaire que enxerga nos sentidos do homem uma forma de alcançar o divino, e a visão mística do poeta rio-grandense que vê no amor a forma mais elevada de culto a Deus. Ambos irão basear-se nas teorias de Swedenborg, mas seus resultados serão diferentes. Enquanto o bardo francês vê correspondências na sinestesia e na musicalidade das palavras, o poeta brasileiro enxerga essas mesmas correspon- 
dências no amor a todas as coisas vivas, e em especial à sua amada. Para Eduardo, a musicalidade das palavras serve como a alavanca que liga o humano ao divino, que faz com que as almas se comuniquem para além de qualquer racionalização, para além de qualquer lógica.

\section{REFERÊNCIAS BIBLIOGRÁFICAS:}

BALAKIAN, Anna. O Simbolismo. São Paulo: Perspectiva, 1985.

BAUDELAIRE, Charles. As Flores do Mal. São Paulo: Difusão Européia do Livro, 1958.

BULFINCH, Thomas. O Livro de Ouro da Mitologia. Rio de Janeiro: Ediouro, 2000.

CESAR, Guilhermino. Notícia do Rio Grande do Sul. CARVALHAL, Tania Franco (Org.). Porto Alegre: Instituto Estadual do Livro e Editora da UFRGS, 1997.

CHADWICK, Charles. O Simbolismo. Lisboa: Lysia, 1975.

FAROUKI, Nayla. La Métaphysique. Paris: Flamarion, 1995.

FOREST, Philippe. Le Symbolisme où Naissance de la Poésie Moderne. Paris: Pierre Bordas et fils Éditeur, 1998.

FRIEDRICH, Hugo. Estrutura da Lírica Moderna: da metade do séc. XIX a meados do séc. XX. São Paulo: Duas Cidades, 1978.

GOMES, Álvaro Cardoso. A Estética Simbolista. São Paulo: Cultrix, 1984.

GRAUBY, Françoise. La Création Mythique à L'Epoque du Symbolisme. Paris: Librarie Nizet, 1994.

GRAVES, Robert. Mitos Gregos. São Paulo: Madras, 2004.

GUIMARAENS, Eduardo. A Divina Quimera. Mansueto Bernardi (Org.). Porto Alegre: Globo, 1944.

Dispersos. Maria Luíza Berwanger da Silva (Org.). Porto Alegre: Libretos, 2002.

MOISÉS, Massaud. O Simbolismo. São Paulo: Cultrix, V. 4, 1966.

MORETTO, Fulvia M. L. Caminhos do Decadentismo Francês. São Paulo: Perspectiva; Edusp, 1989.

MURICI, José Cândido de Andrade. Panorama do Movimento Simbolista Brasileiro. Brasília: Conselho Federal de Cultura e Instituto Nacional do Livro, 1973.

ROUGEMONT, Denis de. O Amor e o Ocidente. Rio de Janeiro: Editora Guanabara, 1980.

SCHÜLER, Donaldo. A Poesia no Rio Grande do Sul. Porto Alegre: Mercado Aberto, 1987.

SPINA, Segismundo. A Lírica Trovadoresca. São Paulo: Edusp, 1996.

TAYLOR, Richard. Metafísica. Rio de Janeiro: Zahar Editores, 1969. 